\title{
CIRCUITOS ESPACIAIS PRODUTIVOS, CÍRCULOS DE COOPERAÇÃO E PATRIMÔNIO CULTURAL CONTEMPORÂNEO: Uma proposta metodológica
}

\section{PRODUCTIVE SPACIAL CIRCUIT, COOPERATION CIRCLES AND CONTEMPORARY CULTURAL HERITAGE: A methodological proposal}

\author{
A. Laura De Bona \& B. Manoel Lemes da Silva Neto \\ Programa de Pós-Graduação em Arquitetura e Urbanismo - POSURB-ARQ; PUC Campinas, \\ Brasil \\ lauradebona@gmail.com \\ manoel.lemes@puc-campinas.edu.br
}

\begin{abstract}
RESUMO
A partir dos conceitos de circuitos espaciais produtivos e dos círculos de cooperação, o artigo discute a produção do Museu do Amanhã e do Sítio Arqueológico Cais do Valongo enquanto bens patrimoniais no cenário da modernização da zona portuária do Rio de Janeiro, chamado Porto Maravilha, em andamento desde 2009. Verifica-se o alto grau de internacionalização desses bens, distanciando-os do lugar em que estão situados para significá-los nos circuitos de cidades globais e da indústria cultural globalizada, sob o pretexto de patrimonialização e culturalização dos bairros de Saúde, Gamboa e Santo Cristo. O objetivo é apresentar o potencial dos circuitos espaciais produtivos e dos círculos de cooperação como ferramentas analíticas com potencial crítico e integrante de políticas de planejamento territorial e propor o conceito de território usado como categoria analítica de natureza crítico-propositiva.
\end{abstract}

Palavras-chave: patrimonialização, circuito espacial produtivo, Porto Maravilha.

Linha de Investigação: Cidade e Ambiente

Tópico: Património e paisagem cultural

\section{ABSTRACT}

Based on the concepts of spacial productive circuits and cooperation circles, the article discusses the production of the Museum of Tomorrow and the Valongo Wharf as heritage assets in the scenario of the modernization of the port area of Rio de Janeiro, called Porto Maravilha, in progress since 2009. There is a high degree of internationalization of these assets, distancing them from the place where they are located to signify them in the circuits of global cities and the globalized cultural industry, under the pretext of patrimonialization and culturalization of the neighborhoods of Saúde, Gamboa and Santo Cristo. The objective is to present the potential of spacial productive circuits and cooperation circles as analytical tools with critical potential and an 


\section{SÃOPAULO15 17 LISBOA $25 \sim 26$ JUN 2020}

integral part of territorial planning policies and to propose the concept of territory used as an analytical category of a critical-propositional nature.

Keywords: patrimonialization, spacial productive circuit, Porto Maravilha.

Research line: City and Environment

Topic: Heritage and cultural landscape

\section{Introdução}

A zona portuária do Rio de Janeiro (RJ) está em processo de modernização desde 2009 acionado pelo projeto de requalificação urbana conhecido como Porto Maravilha. Esse projeto visa reinserir essa região historicamente estigmatizada como subversiva ao circuito econômico e turístico da cidade por intermédio da implantação de equipamentos culturais, realização de grandes eventos nacionais e internacionais, e pelo incentivo à construção de empreendimentos comerciais e residenciais. E mais: pela ressignificação simbólica da zona portuária (Broudehoux, Monteiro, 2017) por meio de estratégias de patrimonialização (Leite, Peixoto, 2009) e culturalização (Vaz, 2004).

Situando a patrimonialização no contexto de uma indústria cultural globalizada (Choay, 2006), e de mercantilização do patrimônio (Paes-Luchiari, 2005) é possível pensar na produção deliberada de patrimônios culturais.

Na medida em que os monumentos, patrimônios e ícones são elementos constituintes da paisagem e que a paisagem pode ser reestruturada por projetos urbanos, esses bens patrimoniais podem ser (e são) instrumentalizados com vistas a uma inversão simbólica planejada.

A história da zona portuária do Rio de Janeiro, e as ações que se empreenderam para banir a imagem estigmatizada de área degradada, fizeram-se acompanhar dessa trajetória criada entre memória e patrimonialização globalizada. 


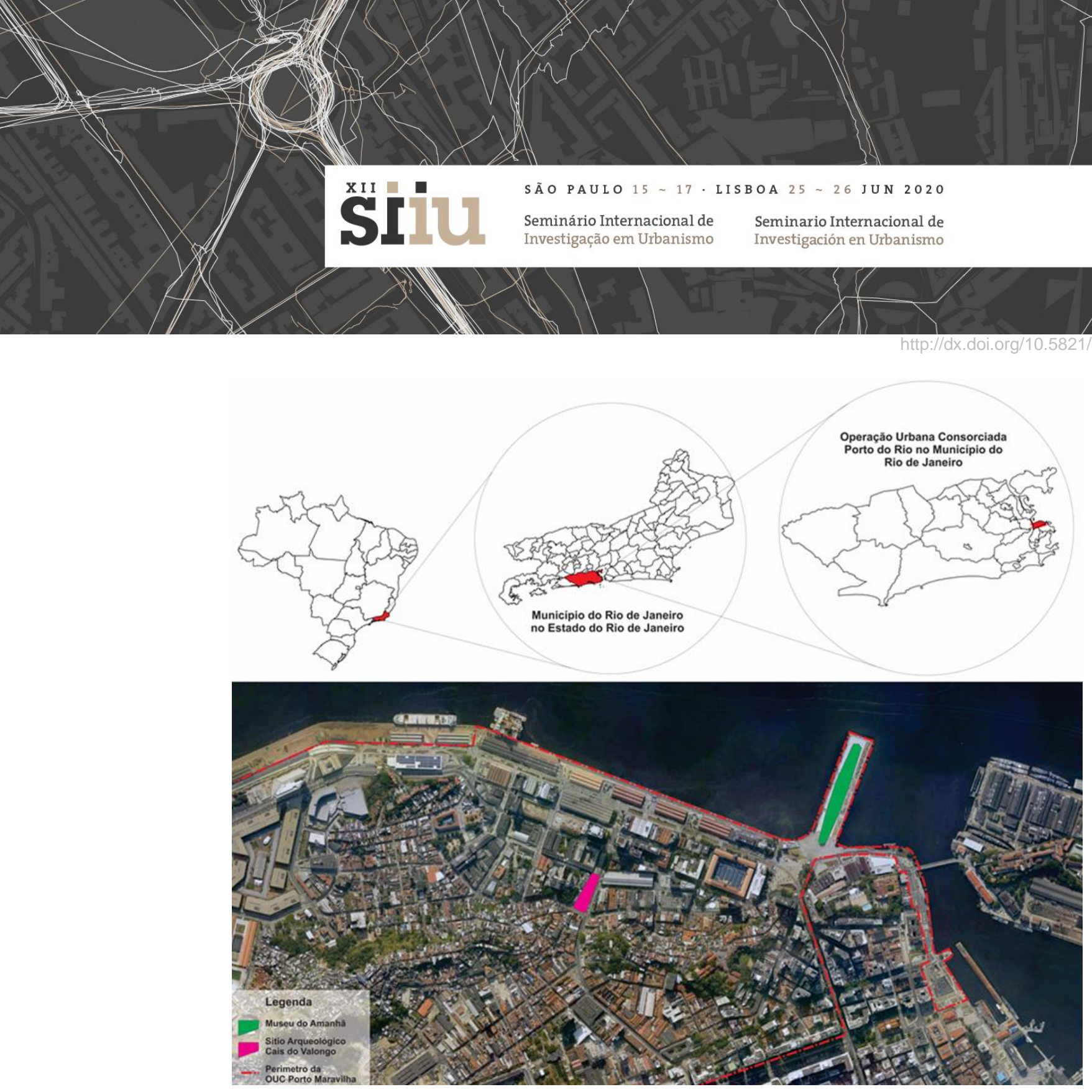

Figura 1 - Localização dos equipamentos culturais analisados, na zona portuária do Rio de Janeiro (RJ). Elaborado pelos autores. Fonte: Data Rio (http://www.data.rio/app/patrimônio-cultural-carioca).

Eis que, no atual estágio do capitalismo, a indústria cultural apropria-se dos valores simbólicos para produzir valores econômicos a serem consumidos em atividades turísticas e imobiliárias.

É o caso do Museu do Amanhã e do Sítio Arqueológico Cais do Valongo.

Esses dois equipamentos revelam exemplarmente a apropriação de bens patrimoniais alicerçados no mercado cultural que se instituiu na zona portuária do Rio de Janeiro através do projeto Porto Maravilha (Figura 1).

Embora o Museu do Amanhã não seja institucionalmente reconhecido como patrimônio tombado, trata-se de um legado da última modernização da zona portuária, juntamente com outros equipamentos culturais implantados a partir de 2009, inclusive no contexto de patrimonialização do Cais do Valongo, (re)descoberto durante obras de infraestrutura do Porto Maravilha em 2011.

\section{Circuitos espaciais produtivos e círculos de cooperação: uma proposta metodológica}

A produção de qualquer objeto é realizada em etapas. No limite, é possível decompor esse objeto e representar a produção individual de cada componente estabelecendo sua cadeia produtiva, composta por relações técnicas e sociais, e que se realiza em diversos lugares. 


\section{XII $\square$ SÃO PAULO15 17 LISBOA $25 \sim 26$ JUN 2020

Essas cadeias produtivas, ou circuitos produtivos, se dão no espaço e a importância de cada processo ajuda a compreender sua organização.

O conceito dos circuitos espaciais produtivos remete ao trabalho desenvolvido pelo Centro de Estúdios del Desarrollo (CENDES), da Universidad Central da Venezuela. Coordenado por Sonia Barrios e Alejandro Rofman, o projeto "MORVEN - Metodologia para o Diagnóstico Regional" (Barrios, 1980) propõe uma metodologia para analisar, sob as particularidades dos países de Terceiro Mundo, a segmentação e especialização de atividades produtivas nos espaços nacionais, considerando os diferentes agentes envolvidos no processo de produção, circulação, troca e consumo (Castillo, Frederico, 2010).

O conceito também é associado à divisão territorial do trabalho, pois identifica a série de etapas do processo de transformação entre o produto principal até o consumo (Santos, 1986). Atingindo frações do território por meio de fluxos materiais e imateriais acionados por empresas, instituições e pessoas, constituem-se círculos de cooperação do processo produtivo que atribuem nexos organizacionais entre espaços geograficamente dispersos (Castillo, Frederico, 2010). Essas etapas incluem relações de ordem econômica, técnica e social, constituintes do processo produtivo, que se relacionam "no" e "pelo" território com diferentes projetos e interesses (Silveira, 2011).

Consequentemente, os circuitos espaciais produtivos traduzem a seletividade espacial mediante a qual o aprofundamento da divisão territorial e internacional do trabalho espelha os lugares segundo a densidade técnica, a densidade informacional e a densidade comunicacional, "atributos que se interpenetram e cuja fusão os caracteriza e distingue" (Santos, 2014, p. 173).

Regiões se constituem historicamente e não são realidades autônomas. São suscetíveis às influências externas. Os circuitos espaciais produtivos revelam, também, a posição particular e relativa que dado território ocupa no conjunto de todos os demais, reiterando a influência das heranças espaciais de produção inerentes à cada lugar.

Agora, transpondo essas noções elementares aos casos em questão, como pensar o circuito espacial produtivo de, por exemplo, um edifício ícone? E um patrimônio mundial? Quais são os agentes envolvidos na produção desses "patrimônios contemporâneos" repletos de dimensões simbólicas que atuam no imaginário popular local?

Sob a ótica dos circuitos espaciais produtivos incidentes na patrimonialização da cidade do Rio de Janeiro, os estudos de caso envolvem a construção e operação do Museu do Amanhã e da inscrição do Sítio Arqueológico do Cais do Valongo como Patrimônio da Humanidade.

Mas há um detalhe. O conceito pode contribuir na compreensão dos circuitos espaciais produtivos e os círculos de cooperação envolvidos, mas sua aplicação não pode ser diretamente transferida. No caso, o que importa são os princípios e as etapas a serem percorridas para se alcançar a explicação dos circuitos espaciais produtivos do Museu do Amanhã e do Cais do Valongo, como equipamento cultural, como patrimônio contemporâneo e no contexto do fenômeno de globalização.

Assim considerada, e obedecendo aos elementos constitutivos do conceito de circuitos produtivos, a construção desses bens patrimoniais pode ser compreendida como instância de produção, sua divulgação como circulação, e o conteúdo produzido e difundido nesses lugares como instância de consumo. Defendemos que a aplicação da metodologia permite identificar a localização geográfica dos agentes responsáveis pela produção desses equipamentos culturais, refletindo a divisão territorial do trabalho que, em tempos de globalização, não se restringe às fronteiras nacionais. 


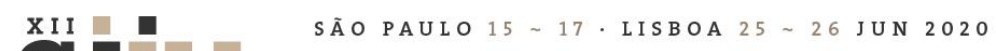

Por se tratar de suportes materiais de memórias, promotores de identidades e valores simbólicos, sua produção deve ser compreendida em totalidade, indo além de matérias-primas e técnicas construtivas.

A metodologia compreende em coletar informações disponíveis online referentes aos colaboradores, responsáveis técnicos e fornecedores envolvidos em atividades relacionadas ao projeto e à construção dos edifícios e acervos., Depois, essas atividades foram categorizadas segundo as ordens econômica, técnica e social e, posteriormente, espacializadas para representar a geografia dos circuitos envolvidos nesse processo de patrimonialização.

Para o circuito espacial produtivo do Museu do Amanhã, obteve-se a colaboração do Instituto de Desenvolvimento e Gestão - IDG¹.

Para o Sítio Arqueológico Cais do Valongo, verificou-se as instituições, empresas e pessoas envolvidas na elaboração do Dossiê de inscrição do bem como Patrimônio da Humanidade junto à UNESCO (IPHAN, PMRJ, 2016).

Nesse caso, o patrimônio histórico tem seu valor simbólico atribuído institucionalmente a posteriori, ou seja, não foi produzido para tal finalidade (Choay, 2006). Destaca-se que o Sítio Arqueológico Cais do Valongo apenas pode ser entendido enquanto patrimônio pelo processo de tombamento. Embora reconhecido enquanto patrimônio no IPHAN (na esfera federal) e em análise pelo IGEPAC (na esfera estadual), no caso da presente análise considerou-se os circuitos envolvidos nas atividades relacionadas a sua candidatura à Lista de Patrimônios da Humanidade.

\section{Os achados da pesquisa no Museu do Amanhã e no Cais do Valongo}

Um painel disponível no hall do edifício do Museu do Amanhã (Figura 2) foi a principal fonte de informações.

Documentadas, as informações ali constantes foram verificadas junto aos profissionais do Museu do Amanhã ${ }^{\text {. }}$ Destaca-se que, no caso de instituições e empresas internacionais, optou-se por considerar a cidade-sede dos agentes, pressupondo-se que as decisões operacionais e econômicas ali se concentram.

\footnotetext{
${ }^{1}$ Reiteramos o agradecimento à IDG / Museu do Amanhã pela disponibilização dos dados utilizados e pelo suporte fornecido pela equipe de pesquisa.

${ }^{2}$ A base documental pode ser verificada em De Bona (2018). Destaca-se que, nas publicações anteriores (De Bona, Silva Neto, 2018; De Bona, 2018; De Bona, Silva Neto, 2019; De Bona) a metodologia foi testada a partir da contabilização dos agentes envolvidos, sendo considerado agora a incidência de total de registros.
} 


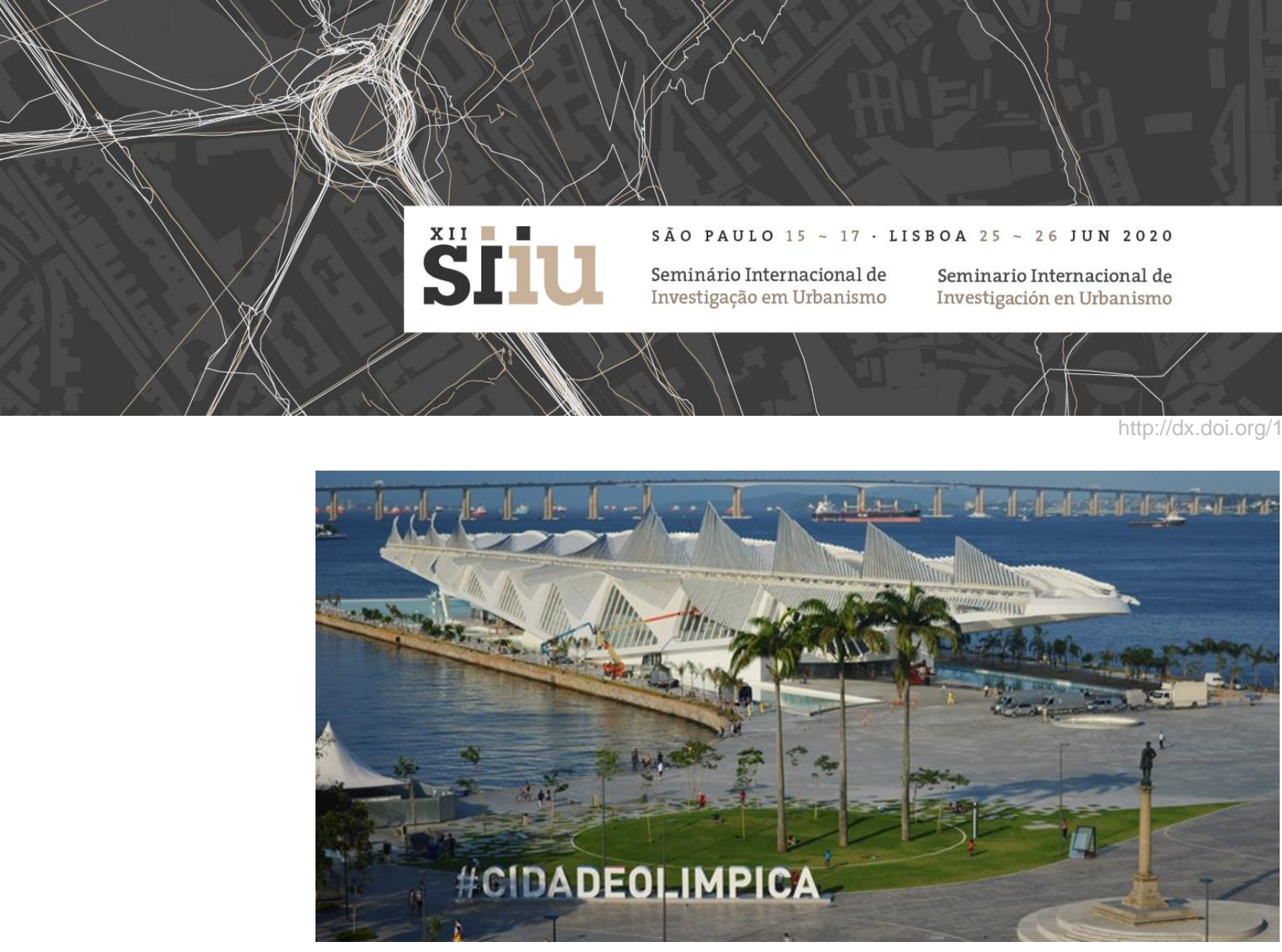

Figura 2 - Museu do Amanhã. Fonte: Domínio Público (https://commons. wikimedia.org/w/index.php?curid=45719417).

A consolidação da base documental (Quadro 1) apresenta todos os agentes identificados, indicando 316 registros categorizados por atividade, e compreendeu a subdivisão segundo ordem e origem do insumo ou produto, observando-se predomínio de registros relacionados a agentes europeus e norte-americanos, no caso dos fluxos originados no exterior, e no eixo Rio-São Paulo, no caso dos fluxos produzidos no Brasil.

A síntese quantitativa do circuito espacial produtivo do Museu do Amanhã revela que em seus círculos de cooperação prevalecem agentes brasileiros em todas as ordens analisadas, sejam eles instituições, empresas ou pessoas. Entretanto, foi possível aprofundar qualitativamente a análise das informações apresentadas.

$\mathrm{Na}$ ordem econômica, a concepção e realização das obras são responsabilidade de empresas e instituições brasileiras, especialmente a Fundação Roberto Marinho e a Concessionária Porto Novo (formada pelas construtoras OAS S.A., Norberto Odebrecht S.A. e Carioca Christiani-Nielsen Engenharia), com apoio das instâncias federal, estadual e municipal de governo.

A gestão da instituição também é responsabilidade da IDG, uma empresa nacional. Entretanto, há empresas internacionais diretamente relacionadas ao funcionamento do Museu, notadamente a Shell como mantenedora, o Banco Santander, como patrocinador máster, e as empresas Engie e IBM, como patrocinadoras.

Quanto a ordem técnica, também se verifica predominância de agentes brasileiros na fabricação de materiais e execução das obras. Porém, as concepções iniciais e definições projetuais de maior relevância, como projeto arquitetônico (Santiago Calatrava LLC), estruturas metálicas (Projeto Alpha Engenharia de Estruturas e Santiago Calatrava LLC), consultoria de projetos (Arup) e concepção museográfica (ORB LLC) foram realizadas por grandes empresas estrangeiras. Os agentes nacionais se restringem ao detalhamento e projetos menores, porém desenvolvidos a partir de projetos idealizados no exterior.

O padrão se mantém na ordem social. Os principais colaboradores de conteúdos são empresas estrangeiras, como a JCDecaux (fornecedora oficial de mídia), THNK School of creative leadership e Dutch Culture Centre of International Cooperation (parceiros internacionais), Cisco e Intel (parceiros tecnológicos), Spotify (player oficial) e Foundation Engie, Newton Fund e British Council (parceiros em projetos especiais).

Quanto aos agentes envolvidos na consultoria de atualização do acervo digital, também há numerosas parcerias internacionais. 


\section{XII $\square$ SÃOPAULO15 17 LISBOA $25 \sim 26$ JUN 2020 \\ Seminário Internacional de \\ Seminario Internacional de \\ Investigação em Urbanismo \\ Investigación en Urbanismo}

A base documental foi mapeada para verificar a disposição geográfica dos agentes que participaram na produção do Museu do Amanhã.

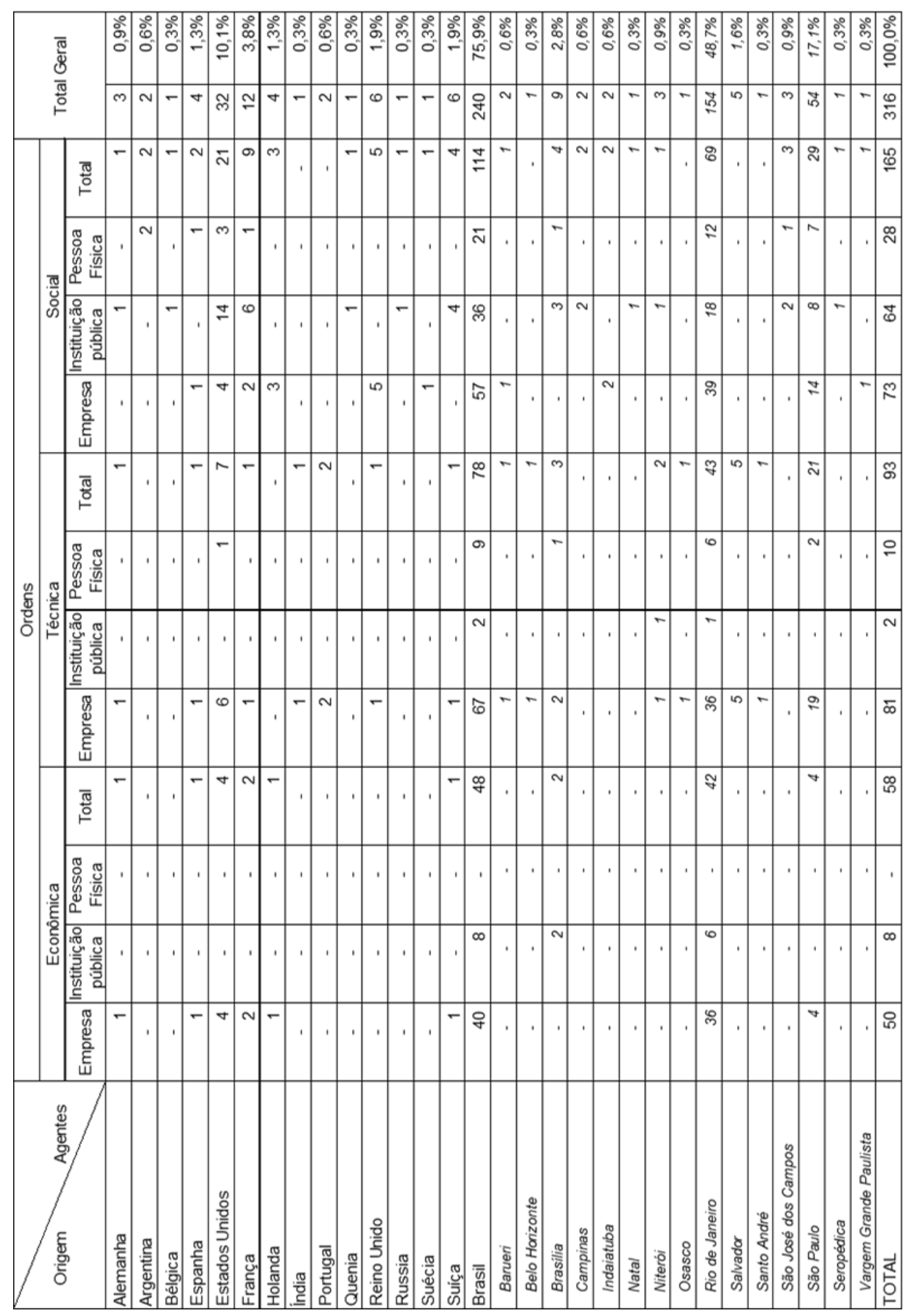

Quadro 1 - Atividades identificadas nos circuitos espaciais produtivos do Museu do Amanhã, RJ (2018). Fonte dos dados primários: De Bona, 2018. 


\section{SÃOPAULO15 17 LISBOA $25 \sim 26$ JUN 2020 \\ Seminário Internacional de \\ Seminario Internacional de Investigação em Urbanismo Investigación en Urbanismo}

Sobre a identificação dos agentes envolvidos no processo de patrimonialização do Sítio Arqueológico Cais do Valongo como Patrimônio da Humanidade (Figura 3), a principal fonte utilizada foi o Dossiê de candidatura do bem à lista de Patrimônio da Humanidade (IPHAN, PMRJ, 2016), sob responsabilidade da Unesco.

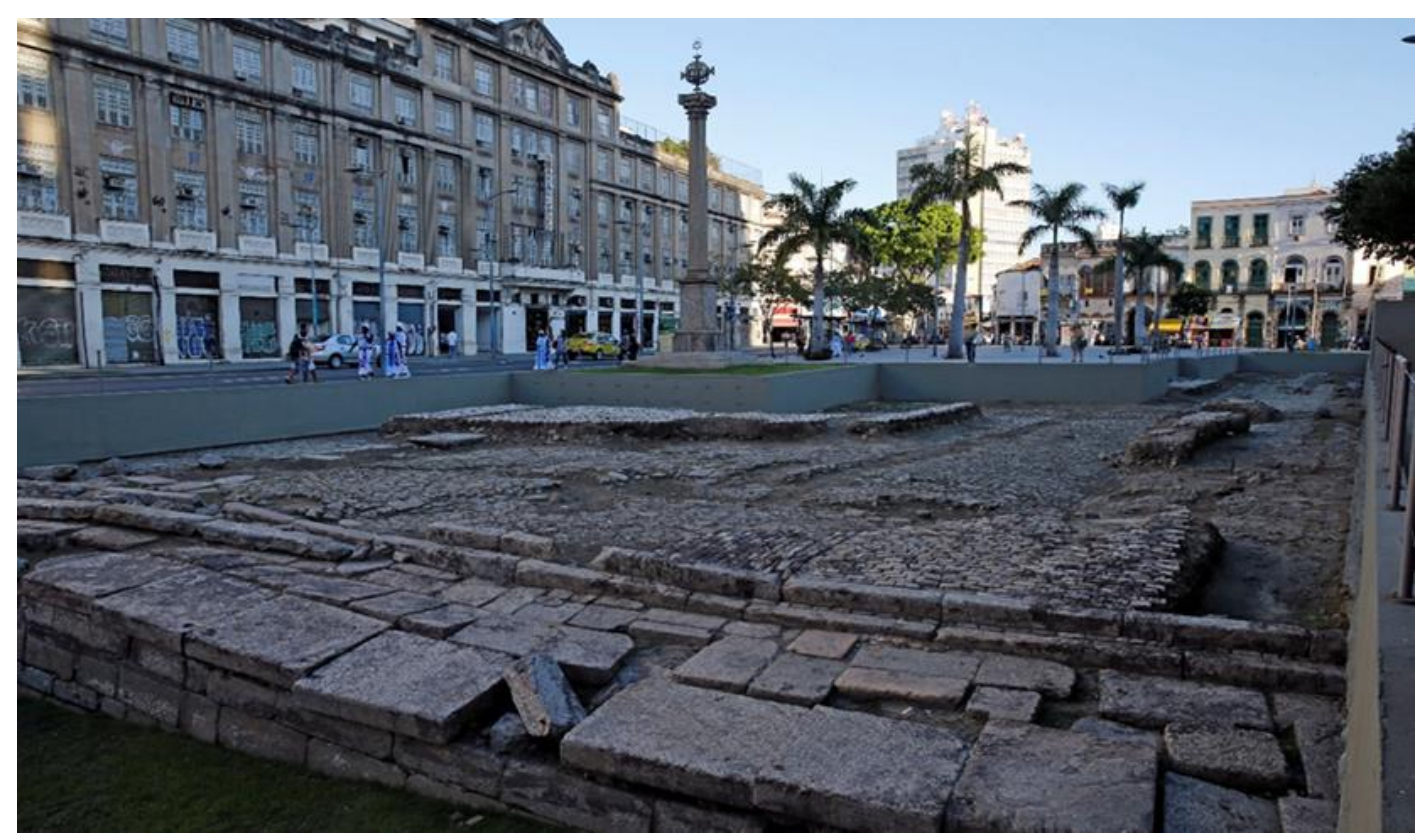

Figura 3 - Cais do Valongo, reconhecido como Patrimônio da Humanidade em 2017. Fonte: Agência Brasil Fotografias (https://commons. wikimedia.org/w/index.php?curid=60831589)

Essa base documentou resultou na identificação de 147 itens (Quadro 2). A síntese quantitativa das informações colhidas contribuiu para informar o entendimento dos círculos de cooperação envolvidos nesse processo através da especificação de quais agentes são empresas, quais são instituições e quais são pessoas físicas ${ }^{3}$.

Verifica-se grande participação de instituições na patrimonialização do Cais do Valongo (em todas as ordens), e destaca-se a participação de organizações sociais ou movimentos da sociedade civil, especialmente na ordem técnica, e nos planos de gestão do bem, na ordem econômica.

Quanto à participação da sociedade civil, foram convidados movimentos sociais que se integraram ao plano na qualidade de membros do conselho consultivo para o tombamento e para proposta de inscrição do bem na Lista de Patrimônio da Humanidade, entre os quais: Quilombo da Pedra do Sal; Conselho Municipal em Defesa do Direito do Negro (COMDEDINE) e o Centro de Articulação de População Marginalizada.

\footnotetext{
${ }^{3}$ No caso da ordem técnica de conteúdo foram considerados outros sítios inscritos na lista de Patrimônio da Humanidade pela Unesco. São lugares tombados por seu valor simbólico, apresentados como referência para justificar o tombamento. Nesses casos, os sítios foram considerados como instituições, visto que há instituições públicas de governo relacionadas a sua gestão. Organizações resultantes de movimentos sociais e indicações de participação da "sociedade civil" foram consideradas como pessoas, por não se configurarem enquanto instituições ou empresas.
} 


\section{XII $\square$ SÃOPAULO15 17 LISBOA $25 \sim 26$ JUN 2020 \\ Seminário Internacional de \\ Seminario Internacional de Investigação em Urbanismo Investigación en Urbanismo}

Também se envolveram representantes da comunidade universitária: Universidade Federal Fluminense; Universidade Federal do Rio de Janeiro; Universidade Federal Rural do Rio de Janeiro; Universidade Estadual do Rio de Janeiro; e, Universidade Federal da Bahia.

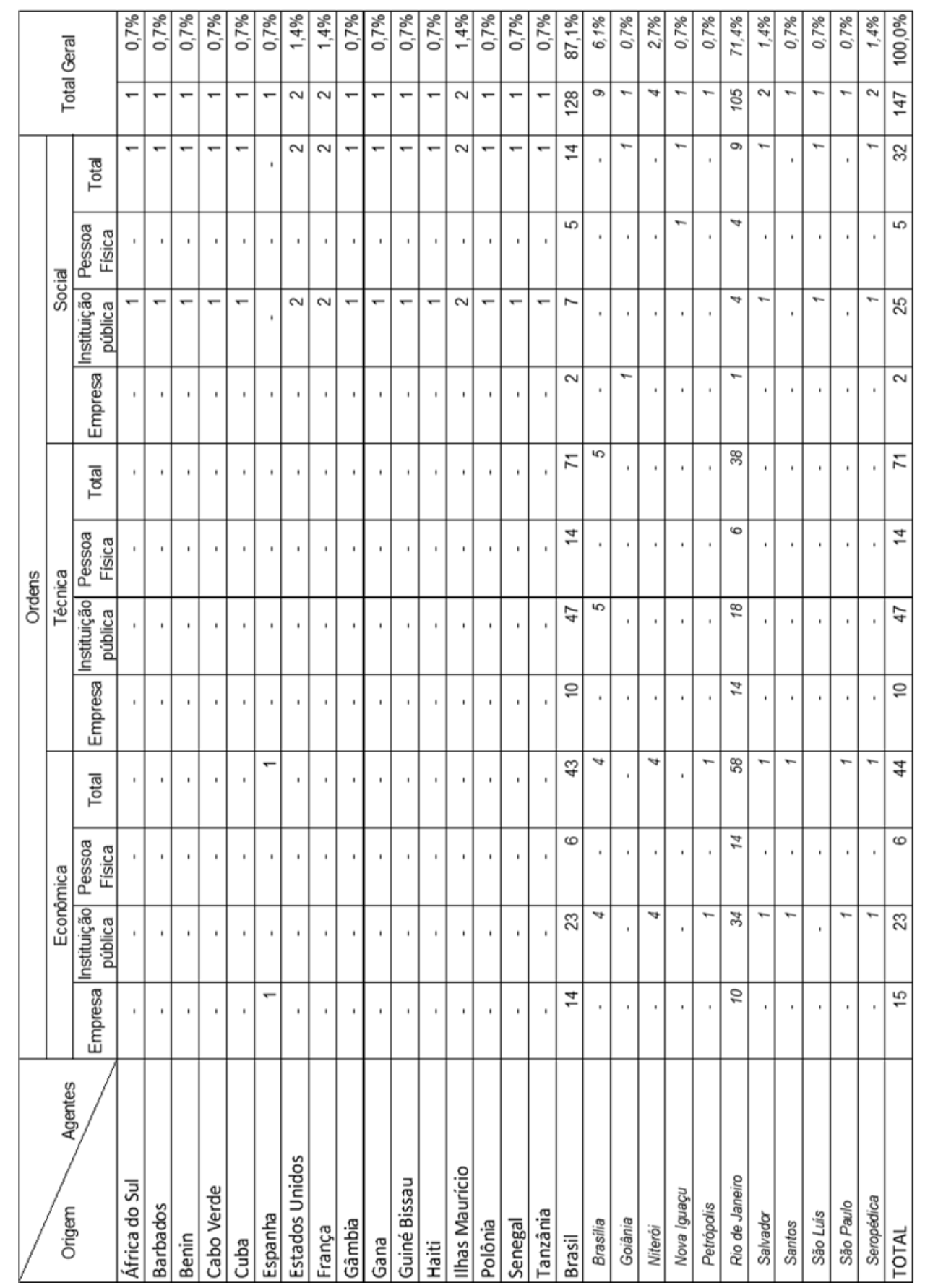

Quadro 2 - Atividades identificadas nos circuitos espaciais produtivos do Cais do Valongo, RJ (2018). Fonte dos dados primários: De Bona 2018. 


\section{XII $\quad$ SÃO PAULO $15 \sim 17 \cdot$ LISBOA $25 \sim 26$ JUN 2020

E museus: Museu Nacional, Instituto Pretos Novos e o Museu de Arte do Rio (MAR).

Agentes-empresas participam na realização das obras (Concessionária Porto Novo, Companhia de Desenvolvimento da Região do Porto - CDURP), incluindo grupos internacionais como a Light (implantação do VLT e reconstrução de infraestrutura urbana) e a Naturgy Energy Group (reconstrução de infraestrutura urbana).

Em relação aos agentes da ordem social, a numerosa participação de instituições estrangeiras se deve à opção de considerar, como referências, projetos de outros bens inscritos na lista de patrimônios da humanidade, sob responsabilidade da Unesco.

Diversos sítios relacionados à escravidão foram indicados, como os Fortes e Castelos na Grande Acra (Gana), a llha de Gorée (Senegal), a llha Kunta Kinteh (Gâmbia) e o Portal do Não Retorno, em Benin.

Embora Benin não estivesse listado entre os bens da humanidade reconhecidos pela Unesco, aquele sítio esteve estreitamente relacionado com o Cais do Valongo. O Portal do Não Retorno era o "ponto de saída" dos escravos. O Cais do Valongo, o "ponto de entrada".

Outros sítios indicados como referência da pertinência do Cais do Valongo como patrimônio da humanidade são os centros históricos de Salvador e São Luís, indiretamente relacionados à escravidão, e sítios de memória sensível, como a Prisão de Robben Island e o centro de concentração Auschwitz-Birkenau, por retratarem o grande sofrimento que pessoas viveram nesses lugares.

Por contribuírem na construção de um ambiente favorável à patrimonialização do Cais do Valongo, outras três entidades foram identificadas como participantes na ordem social do circuito produtivo.

A própria Unesco, considerada em razão do reconhecimento institucional do Cais do Valongo como patrimônio da humanidade ao "Projeto Rota do Escravo: Resistência, Liberdade e Herança", relacionado ao processo de estudo arqueológico do Cais do Valongo.

A Organização das Nações Unidas, que de 2015 e 2024 instituiu a "Década das Pessoas de Descendência Africana", o que contempla diretamente ao Cais do Valongo.

Universidade de Emory, que reuniu informações disponibilizadas por diversas instituições de pesquisa no mundo relacionadas à escravidão, essa universidade organizou o "Banco de Dados do Tráfico de Escravos Transatlântico"4.

\section{Uma geografia para os circuitos espaciais produtivos do Museu do Amanhã e do Cais do Valongo}

O mapeamento dos círculos de cooperação analisados foi produzido a partir do quadro dos circuitos espaciais produtivos e indica que há semelhanças, pontos em comum entre o Museu do Amanhã e o Cais do Valongo

$\mathrm{Na}$ escala global, verifica-se predominância de agentes nacionais, porém com atuação concentrada na execução e operacionalização dos bens, enquanto os grandes projetos e as grandes referências, em ambos os casos, são de origem estrangeira, indicando verticalidades presentes nas decisões estratégicas de produção.

\footnotetext{
${ }^{4}$ Banco de Dados do Tráfico de Escravos Transatlântico. Disponível em http://www.slavevoyages.org/
} 


\section{SÃOPAULO $15 \sim 17 \cdot$ LISBOA $25 \sim 26$ JUN 2020}

Devido à política de internacionalização e pela gestão vinculada a parcerias público-privadas, o Museu do Amanhã (Figura 4) agrega, na ordem econômica, colaboradores internacionais nos Estados Unidos e Europa.

$\mathrm{Na}$ ordem técnica, o padrão espacial identificado permanece, concentrando maior número de colaboradores no Brasil, e apresentando agentes nos Estados Unidos, países europeus e Índia.

Por sua vez, a ordem social é a que contém maior número de agentes envolvidos. Mantém-se o padrão de concentração dos agentes no Brasil, mas há maior diversidade de origem dos colaboradores: Argentina, Estados Unidos, países europeus, Inglaterra, Rússia, Suécia e Quênia. Interessante observar também que se tratam de pessoas físicas, diferentemente do caso do Cais do Valongo, que envolveu entidades e movimentos sociais.

Observa-se que, diferentemente das ordens econômica e técnica, há uma espacialização globalmente mais distribuída.

No caso do Cais do Valongo (Figura 5), a exceção de um colaborador espanhol na ordem econômica, os círculos de cooperação são constituídos por agentes brasileiros. Na ordem econômica e na ordem técnica. Isso decorre da localização do bem patrimonial e da iniciativa de patrimonialização, que se concentrou no âmbito nacional.

Em relação à ordem social, o circuito indica um comportamento semelhante ao do Museu do Amanhã. Há diversos agentes situados no Brasil, mas numerosos agentes em outros países, não apresentando uma concentração nos países da Europa e da América do Norte.

Essa espacialização decorre do fato do Cais do Valongo pretender-se patrimônio da humanidade relacionado à diáspora africana, equiparando-se a outros bens patrimoniais vinculados à temática pelo mundo, notadamente no continente africano e nas américas.

No caso do Museu do Amanhã, há maior grau de internacionalização na produção do edifício e de seu conteúdo. Esse caráter está relacionado às estratégias de gestão da instituição para atração de investimentos privados e colaboração científica com renomados centros de pesquisa estrangeiros.

Esse traço também é perceptível nas escolhas de projeto. Com alto teor de sofisticação técnica, que demandaram a importação de materiais e a colaboração com técnicos estrangeiros, contou-se, especialmente, com uma notoriedade no campo da arquitetura de impacto, o espanhol Santiago Calatrava.

No Cais do Valongo, as evidências indicam outra característica. A produção é altamente concentrada no Rio de Janeiro, e a relação que se manteve com outros lugares no exterior deveu-se ao plano de internacionalizar esse bem patrimonial.

Apesar da participação de agentes situados em outros municípios brasileiros, especialmente Brasília, com o IPHAN, é visível certo descolamento dos agentes brasileiros na produção da nova narrativa construída para o bem.

É notável os esforços na patrimonialização do Cais do Valongo, pela Unesco, em 2016, decorrerem de sua inserção na história global pela narrativa da diáspora africana. Porém, não foi possível identificar o mesmo esforço na divulgação da importância do bem na história nacional, estruturada no âmbito da escravidão. Tombado pelo IPHAN, em 2012, o Cais do Valongo, até o primeiro semestre de 2020, não era tombado na 


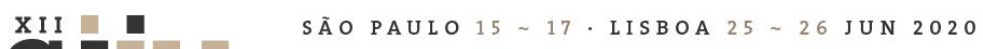

Seminário Internacional de

Seminario Internacional de Investigação em Urbanismo Investigación en Urbanismo

esfera municipal pelo Instituto Rio Patrimônio da Humanidade, e o processo de inscrição do bem junto ao Instituto Estadual do Patrimônio Cultural do Rio de Janeiro é datado de $2018^{5}$.
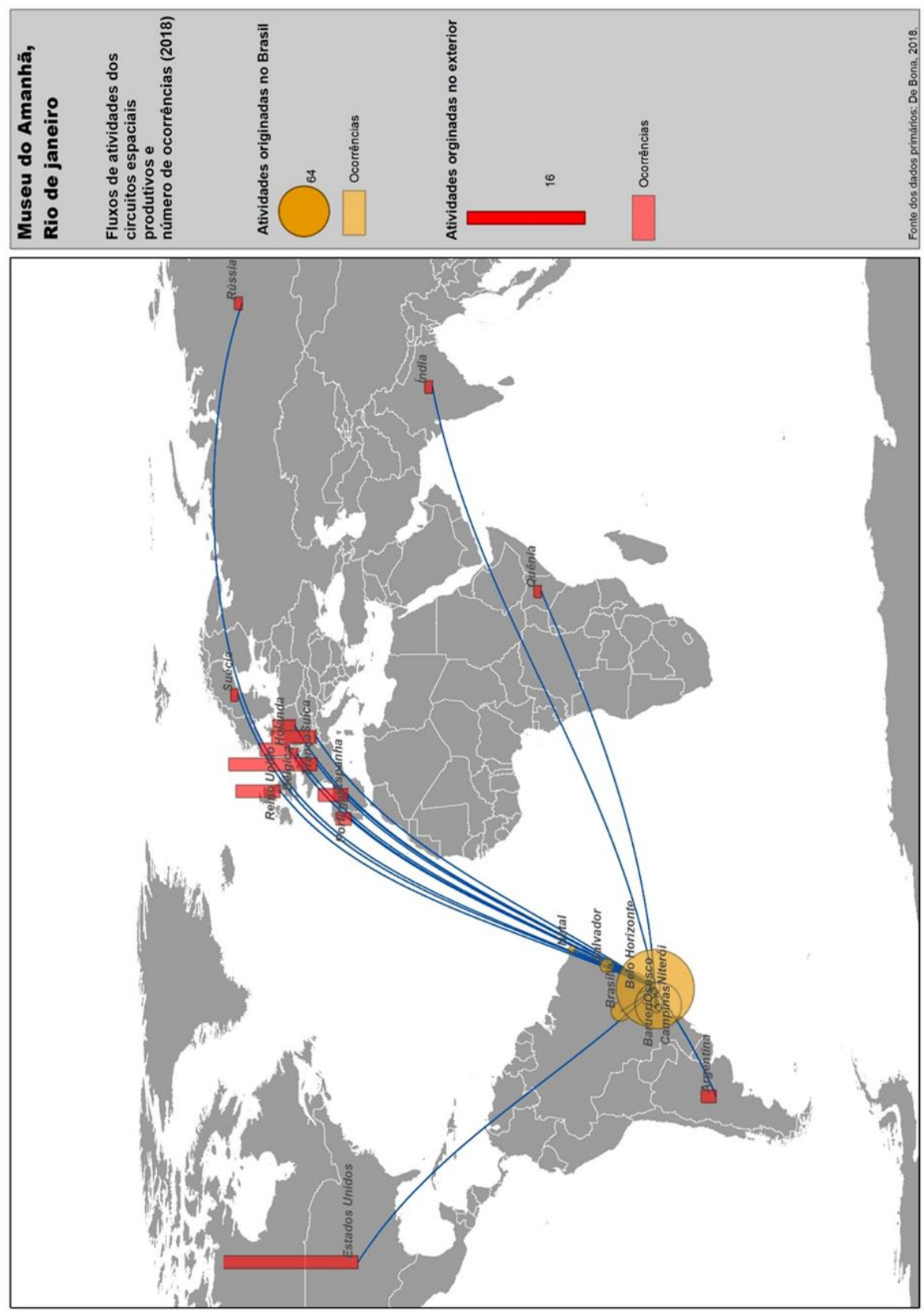

Figura 4 - Atividades identificadas nos circuitos espaciais produtivos do Museu do Amanhã, RJ (2018). Fonte de dados primários: De Bona, 2018.

5 Instituto Estadual do Patrimônio Cultural (INEPAC) -Sítio Arqueológico do Cais do Valongo (Número do processo: E18/001/100095/2018). Tombamento provisório realizado em 03/12/2018. Disponível em <http://www.inepac.rj.gov.br/index.php/bens_tombados/detalhar/518> (Acesso em 05/03/2020) 


\section{XII $\square$ SÃOPAULO15 17 LISBOA $25 \sim 26$ JUN 2020 \\ Seminário Internacional de \\ Seminario Internacional de Investigação em Urbanismo
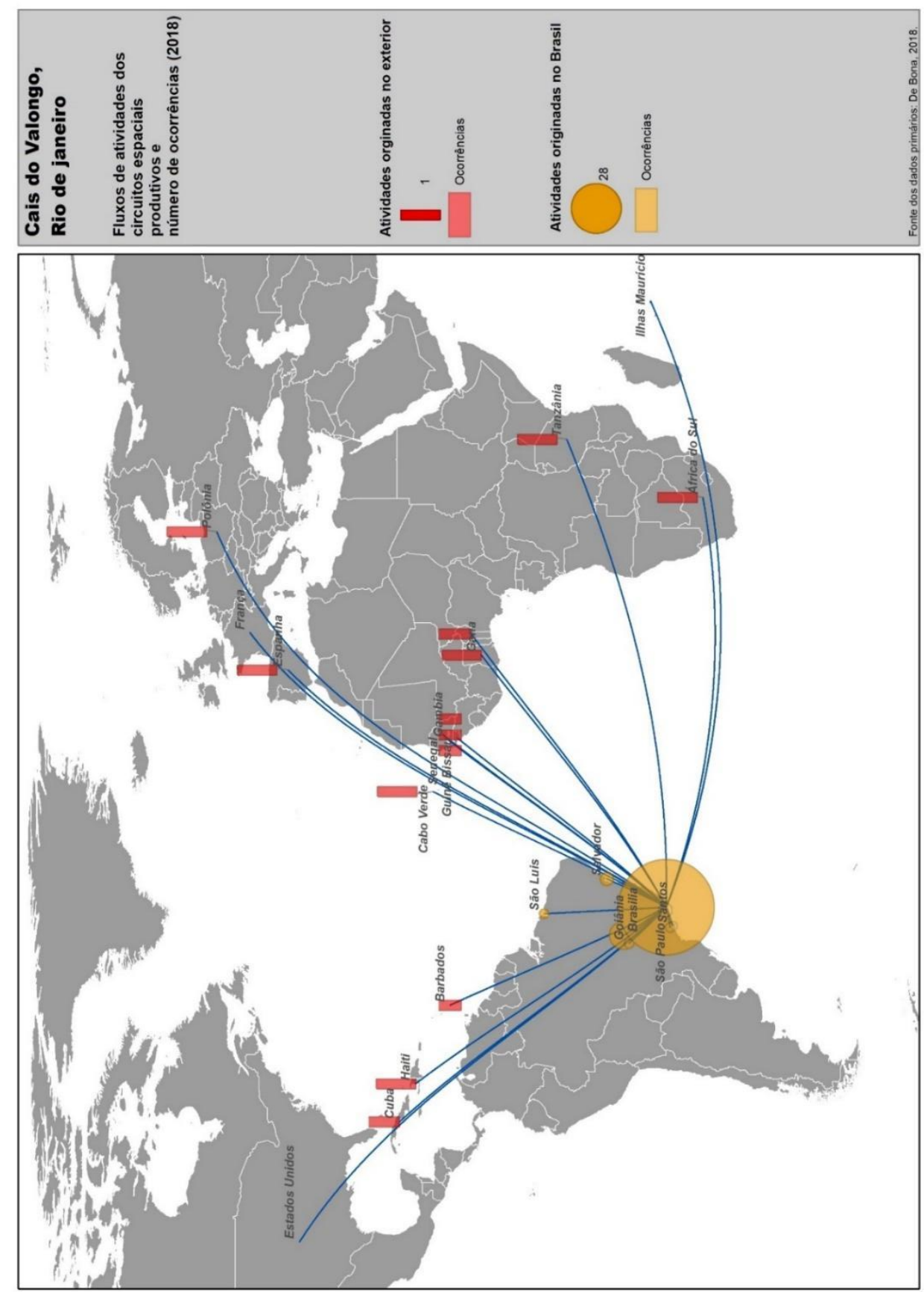


\section{XII $\quad$ SÃO PAULO $15 \sim 17 \cdot$ LISBOA $25 \sim 26$ JUN 2020

Figura 5 - Atividades identificadas nos circuitos espaciais produtivos do Cais do Valongo, RJ (2018). Fonte de dados primários: De Bona 2018.

Em síntese, pode-se relacionar os dois equipamentos analisados pela conexão entre a dimensão local - onde exercem influências de valorização simbólica e econômica em seu entorno - e a dimensão global, que possibilita a atração de investimentos e turistas; tanto o Museu do Amanhã quanto o Cais do Valongo relacionam-se mais com a lógica das cidades globais e dos modelos internacionais de projetos urbanos do que com as dinâmicas sociais da zona portuária.

Isso é indicado pela geografia dos circuitos espaciais produtivos incidentes em ambos os casos.

\section{Considerações finais}

No âmbito da globalização, a produção do espaço na contemporaneidade reproduz padrões de projetos urbanos tidos como casos de sucesso na constituição dos circuitos das cidades globais (Sassen, 2008).

Pela instrumentalização de traços identitários que constituem as singularidades dos lugares, constitui-se industrial cultural globalizada, cuja principal mercadoria têm sido os bens patrimoniais por estratégias de culturalização e patrimonialização. Em consonância, verifica-se a utilização de equipamentos culturais como edifícios âncora de projetos de reestruturação implantados em áreas monofuncionais e centrais da cidade, associadas à sua formação histórica e social (Vaz, 2004). Ao recorrer à arquitetos ilustres no contexto mundial, esses equipamentos culturais inseridos em edifícios icônicos também são apropriados por estratégias de marketing, que promovem esses espaços "regenerados", "revitalizados", para atrair investimentos, turistas e novos serviços (Sánchez et al, 2004).

No caso da zona portuária do Rio de Janeiro, a última modernização proposta foi viabilizada pela aprovação da Operação Urbana Consorciada Porto do Rio, em implantação desde 2009. Legitimada pelos sucessivos projetos de recuperação econômica da região e pela realização de megaeventos esportivos, viabilizou-se diversas intervenções urbanas que visaram a valorização simbólica e econômica da região (Broudehoux, Monteiro, 2017).

Dentre essas intervenções, foram analisados o Museu do Amanhã e o Sítio Arqueológico Cais do Valongo pela aplicação metodológica dos Circuitos Espaciais Produtivos e círculos de cooperação.

Pela verificação da geografia das etapas da produção desses bens patrimoniais, pode-se verificar a o alto grau de internacionalização dos círculos de cooperação que viabilizaram sua produção. O Museu enquanto legado dos megaeventos e ícone da adoção dos modelos das cidades globais. O Cais do Valongo, enquanto Patrimônio da Humanidade, reconhecido internacionalmente por instituições culturais pelo seu valor simbólico na chamada diáspora africana. Em ambos, apesar da grande participação de agentes brasileiros, os responsáveis por decisões estratégicas são estrangeiros, demonstrando verticalidades e a apropriação dos modelos internacionais.

E não precisa ser assim.

A patrimonialização pode contribuir com o elemento de coesão social. Se produzida pelo lugar, para o lugar.

À propósito, essa é a natureza do conceito de território usado proposto por Milton Santos.

Para esse geógrafo, o "caminho que nos libere da maldição da globalização" tem a "sociedade territorial" como base. Isto é, a sociedade indissoluvelmente, territorialmente apreendida aos objetos e ações que a animam. $\mathrm{E}$ é o uso do território, não as formas, que o torna "objeto da análise social". 


\section{XII $\mathbf{S A}$ ÃOPALO $15 \sim 17 \cdot$ LISBOA $25 \sim 26$ JUN 2020

É no uso de fato do território, no território usado, que as contradições articulam as disputas inerentes ao campo político, e onde pode-se verificar as reais demandas da sociedade que devem estruturar as políticas urbanas.

Ao repensar o processo de patrimonialização enquanto mais do que a cristalização de objetos materiais ou imateriais, valoriza-se a complexidade do espaço, fortalecem-se vínculos sociais e a solidariedade conduzidos pelo respeito à diversidade cultural que historicamente caracteriza as cidades.

Não se trata, apenas, de reconhecer institucionalmente os elementos estruturais da identidade coletiva, mas de visibilizar essas expressões culturais para fortalecer grupos sociais e a organização da sociedade.

\section{BIBLIOGRAFIA}

Barrios, S. (1980). Metodologia para el Diagnóstico Regional: MORVEN. Caracas. Recuperado de http://www.ucv.ve/organizacion/vrac/gerencia-de-investigacion-cientifica-y-

humanistica/cendes/publicaciones/textos-completos-cendes.html

Broudehoux, A-M.; Monteiro, J. C. C. S. (2017). Reinventing Rio de Janeiro's old port: territorial stigmatization, symbolic re-signification, and planned repopulation in Porto Maravilha. In: Revista Brasileira de Estudos Urbanos e Regionais (online), n. 3 (v. 19), p. 493-512. Recuperado de https://rbeur.anpur.org.br/rbeur/article/view/5500/pdf

Castillo, R., Frederico, S. (2010). Espaço geográfico, produção e movimento: uma reflexão sobre o conceito de circuito espacial produtivo. In: Sociedade \& Natureza, n. 22, (v.3) p. 461-474). Recuperado de http://www.scielo.br/pdf/sn/v22n3/04.pdf

Choay, F. (2006) Alegoria do patrimônio (4ª Edição) - São Paulo : Estação Liberdade : UNESP.

De Bona, L. (2018). Do porto Maravilha ao Cais: patrimonialização e globalização na zona portuária do Rio de Janeiro. (Dissertação de Mestrado) - POSURB-ARQ : PUC-Campinas : Campinas. Recuperado de http://tede.bibliotecadigital.puc-campinas.edu.br:8080/jspui/handle/tede/1203

De Bona, L. \& Silva Neto, M. L. (2018). A construção de (no) patrimônio: considerações sobre o Museu do Amanhã - RJ. In: Anais do V Encontro Nacional da ANPARQ (p. 5216-5238). Salvador : Anparq. Recuperado de https://repositorio.ufba.br/ri/bitstream/ri/27744/17/eixo-3.pdf

. (2019). Por uma outra patrimonialização das belas paisagens cariocas: ou, pequenos achados de pesquisa sobre o Porto Maravilha. In: Anais do XVIII Encontro Nacional da ANPUR (p. 1-35). Natal : Anpur. Recuperado de http://anpur.org.br/xviiienanpur/anaisadmin/capapdf.php?reqid=1109

Instituto do Patrimônio Histórico e Artístico Nacional \& Prefeitura Municipal do Rio de Janeiro - IPHAN \& PMRJ. (2016). Sítio Arqueológico Cais do Valongo: proposta de inscrição do na lista do patrimônio mundial. Rio de Janeiro.

Leite, R. P. \& Peixoto, P. (2009). Políticas urbanas de patrimonialização e contrarrevanchismo: o Recife Antigo e a Zona Histórica da Cidade do Porto. In: Cadernos Metrópole (v.21), p. 93-104. Recuperado de https://revistas.pucsp.br/index.php/metropole/article/view/5957

Paes-Luchiari, M. T. D. (2005). A reinvenção do patrimônio arquitetônico no consumo das cidades. In: GEOUSP - Espaço e Tempo (no 17), p. 95-105. Recuperado de http://geografia.fflch.usp.br/publicacoes/Geousp/Geousp17/Artigo6_Maria.pdf 


\section{SÃOPAULO15 17 LISBOA $25 \sim 26$ JUN 2020}

SÁNCHEZ, F.; BIENENSTEIN, G.; CANTO, B. L.; GUTERMAN, B. C; BENEDICTO, D. B. M.; PICINATTO, L. (2004). Produção de sentido e produção do espaço: convergências discursivas nos grandes projetos urbanos. In: Revista paranaense de desenvolvimento, n. 107, Curitiba. Recuperado de https://dialnet.unirioja.es/ejemplar/375592

Santos, M. (1986). Circuitos espaciais da produção: um comentário. In: Souza, M. A. A. \& Santos, M.: A construção do espaço (p. 121-134). São Paulo : Nobel.

. (1999) O território e o saber local: algumas categorias de análise. In: Cadernos IPPUR (ano XIII, № 2), p. 15-26. Recuperado de https://revistas.ufrj.br/index.php/ippur/issue/viewFile/277/86 . (2014). A natureza do espaço: Técnica e tempo, razão e emoção (4⿳亠口冋 Edição). São Paulo : Editora da Universidade de São Paulo.

Sassen, S. (2008). As diferentes especializações das cidades globais. In: Arquitextos, São Paulo, ano 09, n. 103.00, Vitruvius. Recuperado de https://www.vitruvius.com.br/revistas/read/arquitextos/09.103/87/pt

Silveira, M. L. (2011). Território usado: dinâmicas de especialização, dinâmicas de diversidade. In: Ciência Geográfica - Bauru - XV - Vol. XV - (1), p. 4-12. Recuperado de http://www.agbbauru.org.br/publicacoes/revista/anoXV_1/AGB_dez2011_artigos_versao_internet/AGB_dez20 11_01.pdf

Vaz, L. F. (2004). A "culturalização" do planejamento e da cidade: novos modelos? In: Territórios urbanos e políticas culturais - Cadernos PPG-AU/UFBA (Vol. 3, edição especial), p. 31-42. 